\title{
Linear array of multi-substrate tracts for simultaneous assessment of cell adhesion, migration, and differentiation
}

\author{
Ricardo A. Moreno-Rodriguez¹, Edward L. Krug1', Leticia Reyes², and Roger R. Markwald1 \\ ${ }^{1}$ Department of Regenerative Medicine and Cell Biology and ${ }^{2}$ Department of Pharmacology, Medical \\ University of South Carolina, Charleston, SC
}

BioTechniques 63:267-274 (December 2017) doi 10.2144/000114619

Keywords: cell migration; wound healing; gap closure assays; differentiation assay

Cell migration, which is central to a wide variety of life processes, involves integration of the extracellular matrix (ECM) with the internal cytoskeleton and motor proteins via receptors spanning the plasma membrane. Cell migration can be induced by a variety of signals, including gradients of external soluble molecules, differences in ECM composition, or electrical gradients. Current in vitro methods to study cell migration only test one substrate at a time. Here, we present a method for assessing cell adhesion, migration, and differentiation in up to 20 different test conditions simultaneously, using only minute amounts of target substrate. Our system, which we call the linear array of multi-substrate cell migration assay (LAMA), has two configurations for direct comparison of one or two cell types in response to an array of ECM constituents under the same culture conditions. This culture model utilizes only nanogram amounts of test substrates and a minimal number of cells, which maximizes the use of limited and expensive test reagents. Moreover, LAMA can also be used for high-throughput screening of potential pharmaceuticals that target ECM-dependent cell behavior and differentiation.

Cell migration is fundamental to many biological processes, including normal or abnormal embryonic development, immune responses, wound healing, organ regeneration, cell metastasis, and tissue bio-fabrication (1-5). Cells can migrate passively through the circulatory system (3) or actively in 2-D cultures, 3-D cultures or in vivo onto the extracellular matrix (ECM) (2). A collective of cells can translocate as a multicellular sheet/group/cohort, as in gastrulation, neurulation, heart fusion, vascular sprouting, etc. (2-4). Singlecell migration can be: (i) amoeboid or fast moving, as occurs with cancer cells and leukocytes; or (ii) mesenchymal or slow moving, as occurs with fibroblast and mesenchymal cells during the epithelial-mesenchymal transformation
(EMT). Cells can change movement from amoeboid to fibroblastic or vice versa (6). The nuances of cell migration are governed by a balance between extracellular cues (signaling molecules, ECM, basement membrane, and proteases) (7), transduction of those cues through receptor-ligand systems, and the dynamics of the cytoskeleton or cellular motors (8). Migratory cues/signals can be either soluble (as in chemotaxis and chemokinesis) or immobilized to the substrate without or with chemical (as in haptotaxis) or electrical gradients (as in galvanotaxis) $(8,9)$.

The Boyden chamber and scratchwound assays are classical methods for studying chemotaxis, cell invasion, and cell motility dynamics (10-12). New technologies such as microfluidic chambers (13-18), capillary techniques $(19,20)$, galvanotaxis assay (21-23), Radius CytoSelect Cell Migration Assay (24), electric cell substrate impedance sensing (ECIS) assay (25), scratchwound assay (26), gap closure assay (27), and 3-D collagen/fibrin gels $(28,29)$ have been developed to provide more in vivo-like conditions to assess a wide array of motility mechanisms. Most of these systems assess only one substrate at a time or depend on the adsorption capacity of the glass or the dispersion capacity of ink-jet printer nozzles $(30,31)$. While the latter, which provides a means of printing ECM constituents, affords flexibility of pattern and minimizes the amount of reagent used, it has two undesirable characteristics: one is small droplet size

\section{METHOD SUMMARY}

The linear array of multi-substrate cell migration assay (LAMA) culture system comprises a linear parallel array of up to 20 covalently immobilized protein substrates. Two different configurations of the LAMA system can be used to assess cell migration versus cell differentiation in response to an array of extracellular constituents. 
(30-80 pl), which results in an array of circles/ellipses that only cover $~ 80 \%$ of the surface target, and the second is that the droplet dries quickly, given its small size, as it is delivered over the glass, forming a gradient of denatured substrate associated with each droplet in accordance with its geometry. One way to circumvent this issue is to use cross-linking agents to covalently attach target proteins in a more native conformation. Aminosilanized glass slides offer a means for covalently attaching target proteins using varied cross-linking reagents (32). A variety of residues can be used (e.g., sulfhydryl or amino side groups) to optimize retention of functional structure, with amine-based immobilization being perhaps the most common means for attaching proteins, since not all proteins have an exposed cysteine. Regardless of how proteins are attached to the substrate, numerous variables remain concerning the extent of native protein conformation preservation (33-35).

In order to effect a more homogenous distribution of the protein, we have developed a means of preparing a linear and parallel arrangement of multiple target proteins or test compounds (up to 20) in nanogram amounts to study cell adhesion, migration, and differentiation on limited numbers cells. We call this system linear array of multi-substrate cell migration assay (LAMA). LAMA covalently joins ECM proteins to a glass slide, making the assay compatible with standard microscopic methods for cell migration analysis (e.g., time-lapse video microscopy or immunohistochemistry).

\section{Materials and methods}

The following reagents were used in this study: 3-aminopropyltriethoxysilane (aminosilane reagent) (Pierce/Thermo Fisher Scientific, Waltham, MA); coupling buffer (PBS-EDTA; Sigma-Aldrich, St. Louis, MO) (50 mM phosphate, 0.15 $\mathrm{M} \mathrm{NaCl}, 10$ mM EDTA, pH 7.2); crosslinker (Sulfo-LC-SPDP; Pierce/Thermo Fisher Scientific); fibronectin from bovine plasma (Sigma-Aldrich); hyaluronic acid (Sigma-Aldrich); BSA (Sigma-Aldrich); FBS (Gibco, Waltham, MA); nerve growth factor (NGF) (Promega, Madison, WI); recombinant periostin (Biovendor, Asheville, NC); collagen I (rat tail) and

\section{LAMA-M Migration Assay LAMA-D Differentiation Assay}
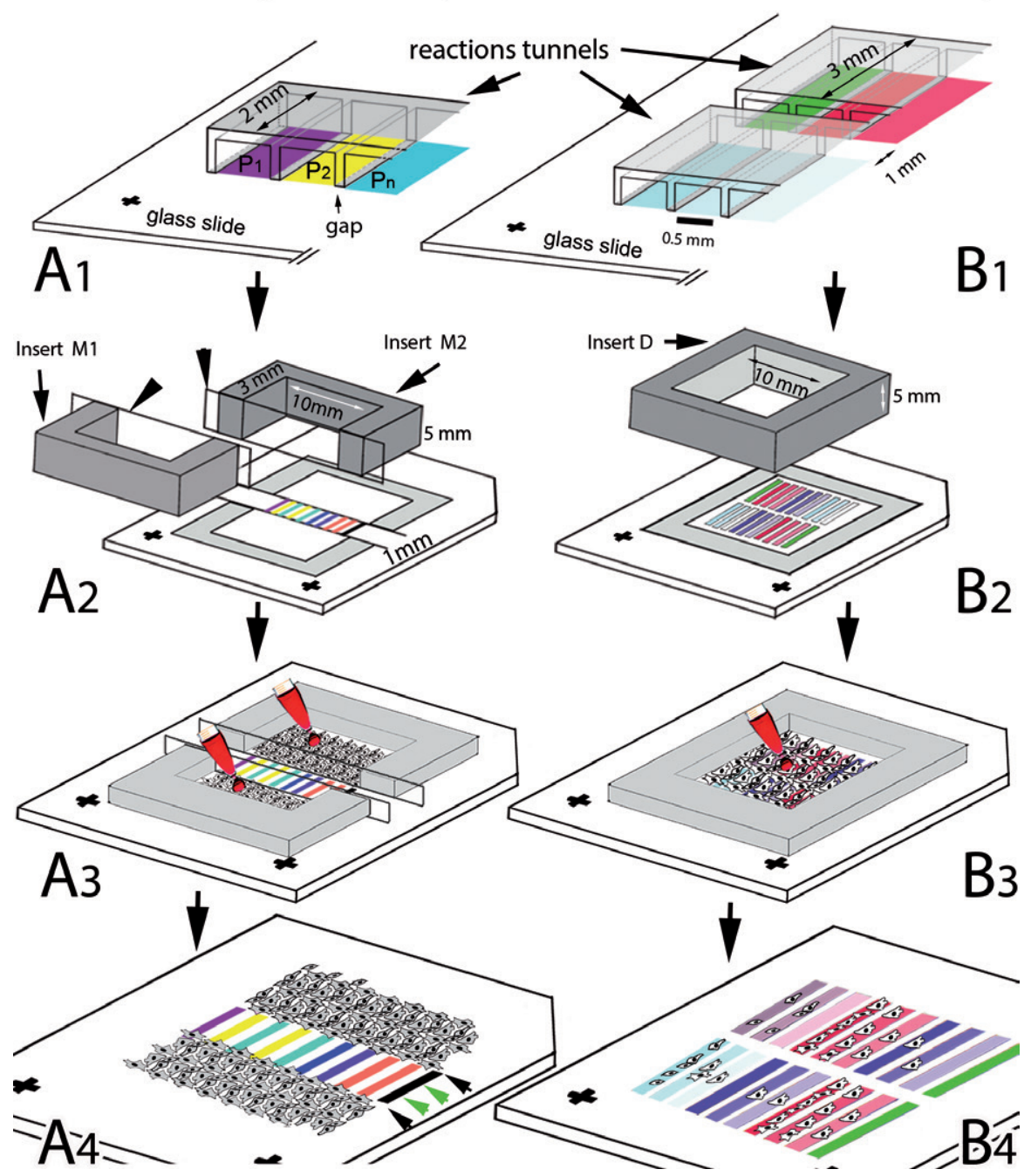

Figure 1. Linear array of multi-substrate cell migration assay (LAMA) tracts for simultaneous assessment of cell adhesion, migration (LAMA-M), and differentiation (LAMA-D). The 10 reaction tunnels, which were the most important part of the present study, were made in Sylgard 184. The dimensions for each LAMA-M tunnel were: width, $0.5 \mathrm{~mm}$; height, $0.6 \mathrm{~mm}$; length, $2 \mathrm{~mm}$; gap between tunnels, $0.3 \mathrm{~mm}$ (A1). For LAMA-D, the only change was an increase in length to $3 \mathrm{~mm}$ (B1). The slide ( $\mathrm{A} 1$ or B1) was derivatized with an aminosilane reagent to add $\mathrm{NH}_{2}$ groups, and the reaction tunnel mold was affixed to the glass surface. Test proteins were covalently linked to the glass within the channels by first adding the bifunctional maleimide activated linker, washing with PBS, and then adding the proteins of interest (represented by different colors) or using the same protein at different concentrations (different intensities of the same color). After attachment of the protein to the glass, the reaction tunnels were detached, the slide was washed, and unreacted sites were blocked with poly-lysine-PEG. (A2) Inserts $\mathrm{M} 1$ and M2 for the migration assay were made with $2 \mathrm{C}$-shaped Sylgard molds (3-mm wide $\times 10-\mathrm{mm}$ long $\times 5$-mm high). The $\mathrm{M}$ inserts were affixed to the slide adjacent to the printed parallel target proteins, and the open side was then closed using a cut coverslip $(7 \times 15 \mathrm{~mm}$, see arrow heads) to form wells (maximum volume: $150 \mu \mathrm{l}$ ) separated $1 \mathrm{~mm}$ from each other. (A3) Cells were added (red pipet) to each well and incubated for $7 \mathrm{~h}$ at $37^{\circ} \mathrm{C}$ to allow cells to attach to the non-derivatized surface prior to removal of the glass slide barrier. The dish was washed with warm medium to remove non-adherent cells. (A4) Migration evaluation. The time zero of the migration assay was considered to be when the inserts were removed, and the cells were at the starting point (back arrow head). The end of the experiment was considered to be when the cells met in the center of the 1-mm gap at the interface with the derivatized target protein array or when the cells were closing that gap (green arrowheads). Migration was evaluated as the difference between the initial position (black arrowheads) and the final position of the cells in the gap (green arrowheads). (B2) Insert D for the adhesion and differentiation assay. A square frame made of Sylgard (10-mm per side $\times 5-\mathrm{mm}$ high; maximum volume: $500 \mu \mathrm{l}$ ) was affixed to the glass slide surrounding the target protein array to create the culture chamber. (B3) The center well was seeded with $500 \mu \mathrm{l}$ cell suspension and incubated at $37^{\circ} \mathrm{C}$ to allow adhesion to the target proteins. The Sylgard enclosure was removed after a $24 \mathrm{~h}$ incubation, and the slide was washed with warmed medium to remove non-adherent cells. This point is considered time zero. (B4) After 5 days, with medium changed every other day, cultures could be assessed for the expression of differentiation markers. 
collagen IV (mouse) from BD Biosciences (San Jose, CA).

\section{Chamber preparation}

The cell migration and cell differentiation chambers were prepared in three steps: mold preparation, protein linkage, and chamber assembly:

Mold preparation. All of the master patterns were handmade on acrylic or glass and were a mirror image of the mold. The molds were made from Sylgard 184 (Dow Corning, Midland, MI) with a mix ratio of $10: 1(\mathrm{v} / \mathrm{v})$ and cured at $45^{\circ} \mathrm{C}$ for $4 \mathrm{~h}$. The plastic housing of a Costar syringe filter (Cat. \#8110; Corning, Waltham MA) was disassembled, and the internal baffle ridges were used as a mirror template for creating Sylgard molds comprising multiple reaction tunnels, each $0.5-\mathrm{mm}$ wide $\times 0.6-\mathrm{mm}$ high, separated by a gap of $0.3 \mathrm{~mm}$. The resulting mold was cut with a single-edged razor blade to 2-mm long for LAMA-M (Figure 1A1) (maximum volume: $0.6 \mu \mathrm{l}$ ) or 3-mm long for LAMA-D (Figure 1B1) (maximum volume: $0.9 \mu \mathrm{l}$ ). The C-shaped culture inserts M1 and M2 for LAMA-M (Figure 1A2) were prepared by adhering glass blocks $(5-\mathrm{mm}$ high $\times$ 3-mm wide $\times 10-\mathrm{mm}$ long) to a Petri dish, then attaching a glass slide vertically to the long axis of the block and subsequently flooding the block with Sylgard, which was allowed to cure and then trimmed with a razor blade to produce 2-mm thick walls (maximum volume: $150 \mu$ l). The vertical glass slide was carefully replaced with a glass coverslip (Corning) that had been cut to $7-\mathrm{mm}$ high $\times 15-\mathrm{mm}$ long and previously coated with a thin layer of Sylgard (after curing at $45^{\circ} \mathrm{C}$ for $4 \mathrm{~h}$ ) to complete the culture insert (Figure 1A2). The squareshaped culture inserts for LAMA-D (Figure 1B1) were prepared by a similar process to yield constructs with an inner dimension per side of $10-\mathrm{mm}$ long $\times 5-\mathrm{mm}$ high (maximum volume: $500 \mu \mathrm{l}$ ).

Protein linking. This process was divided into several stages (Figure 1, A1 and B1): (i) Glass slide derivatization: Fisherbrand Superfrost Plus microscope slides (Cat. \#12-550-15; Fisher Scientific, Waltham, MA) were cut to 23 $\times 25 \mathrm{~mm}$ (with the right corner notched as an orientation marker), washed in a bath of saturated $\mathrm{NaOH}$ in ethanol for 5 min, then rinsed in ethanol followed by distilled water, and air-dried. Cleaned glass slides were immersed in a $2 \%$ solution of 3-aminopropyltriethoxysilane in acetone for $30 \mathrm{~s}$, then rinsed with dry acetone and air-dried. Individual slides were put inside a Falcon cell culture dish $(35 \times 10 \mathrm{~mm})$. The bottom surface of the channel molds was lightly covered with Sylgard $184(10: 1 \mathrm{v} / \mathrm{v})$ and then placed onto the glass slide and allowed to cure at $45^{\circ} \mathrm{C}$ for $4 \mathrm{~h}$. This procedure prevents cross-contamination between channels when applying substrates. (ii) Maleimide activation: The aminosilylated glass surface was covered with $5 \mathrm{~mL}$ crosslinker solution (Sulfo-LC-SPDP; 2 mg dissolved in $1 \mathrm{~mL}$ PBS-EDTA, $\mathrm{pH}$ 7.2), incubated for $1 \mathrm{~h}$ at room temperature, then rinsed with coupling buffer, washed with water, dried, and stored desiccated at $4^{\circ} \mathrm{C}$ for later use. (iii) Protein coupling: Each tunnel was filled with approximately 1 $\mu \mathrm{l}$ of the test protein solution (10-100 mg/ $\mathrm{mL}$ in PBS-EDTA), using a micropipette with an Eppendorf microloader tip, then incubated for $4 \mathrm{~h}$ at room temperature followed by rising with coupling buffer to remove any unbound protein (36). (iv) Blocking residual active sites: Each tunnel was filled with $1 \%$ BSA or $1 \mathrm{mM}$ glycine, then incubated for $2 \mathrm{~h}$ at room temperature to block any unreacted maleimide sites. (v) Mold removal: The position of the tunnel mold was marked by adhering a sterile piece of paper containing a laserprinted image of the tunnels and mold to the underside of the slide and aligned to orientation marks on the slide. The mold was subsequently removed carefully using forceps, and the imprinted surface was covered for 30 min with PLL-g-PEG to inhibit cell attachment to non-derivatized areas of the slide. The PLL-g-PEG solution was prepared as described by Huang et al. (37). Briefly, $84 \mathrm{mg}$ of poly-Llysine hydrobromide (molecular weight: 20 $\mathrm{kDa}$ ) (Sigma-Aldrich) was dissolved in 1.05 $\mathrm{mL} 50 \mathrm{mM}$ sodium borate buffer ( $\mathrm{pH}$ 8.5). Following dissolution of the poly-L-lysine hydrobromide, $216 \mathrm{mg}$ of $\mathrm{N}$-hydroxysuccinimidyl ester of methoxypoly-(ethylene glycol) propionic acid (molecular weight: 2 kDa) (Shearwater Polymers, Inc., San Diego, CA) was added, and the reaction was allowed to proceed for $6 \mathrm{~h}$ at room temperature. The resulting reaction mixture was dialyzed (Spectra-Por, 6-8 kDa cutoff; Spectrum, Waltham, MA) for $24 \mathrm{~h}$, first against a 1000-fold excess of PBS (pH 7.4) overnight and then against deionized water for an additional $24 \mathrm{~h}$.
The first-ever

aliquoting pipet controller

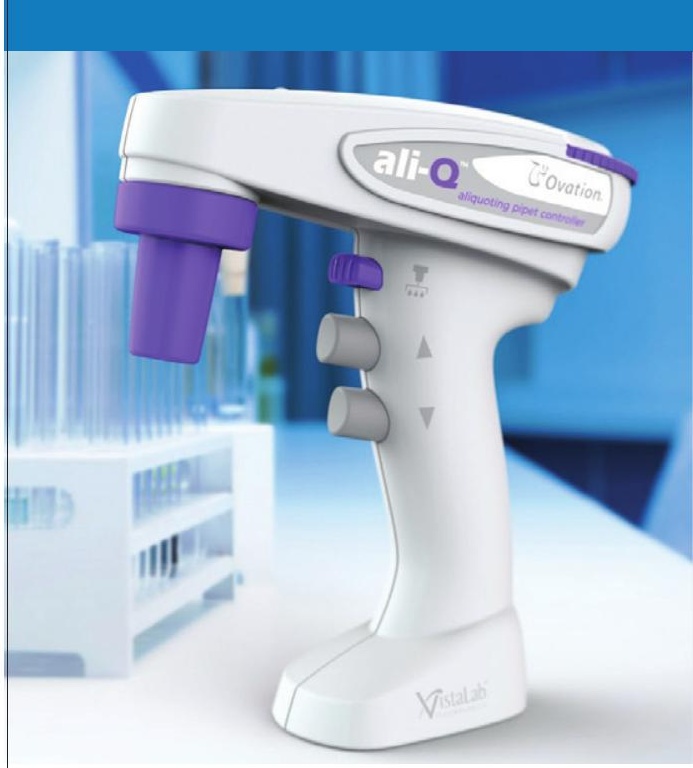

\section{One-button aliquoting}

Get accurate and precise aliquots without the need to "eyeball" the meniscus.

- Faster aliquoting with the press of one button.

- Also aspirates and dispenses like other pipet controllers.

- Uses any size or brand serological pipet.

\section{Use VistaLab ${ }^{\text {TM }}$ Wobble-not $^{\text {TM }}$} serological pipets with ali-Q for the ideal pipetting system.
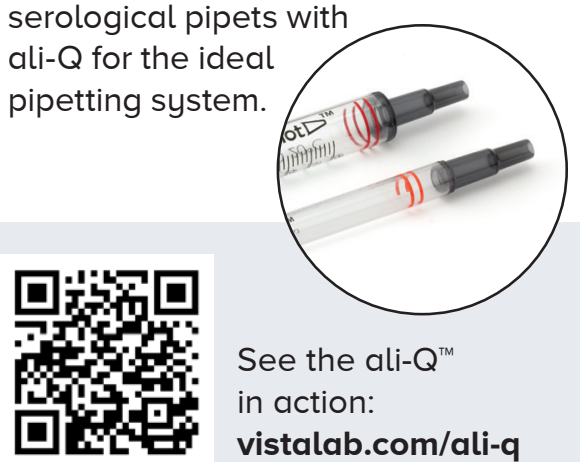

See the ali- $Q^{\text {m }}$ in action: vistalab.com/ali-q 


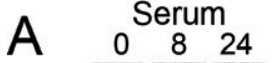

Coll
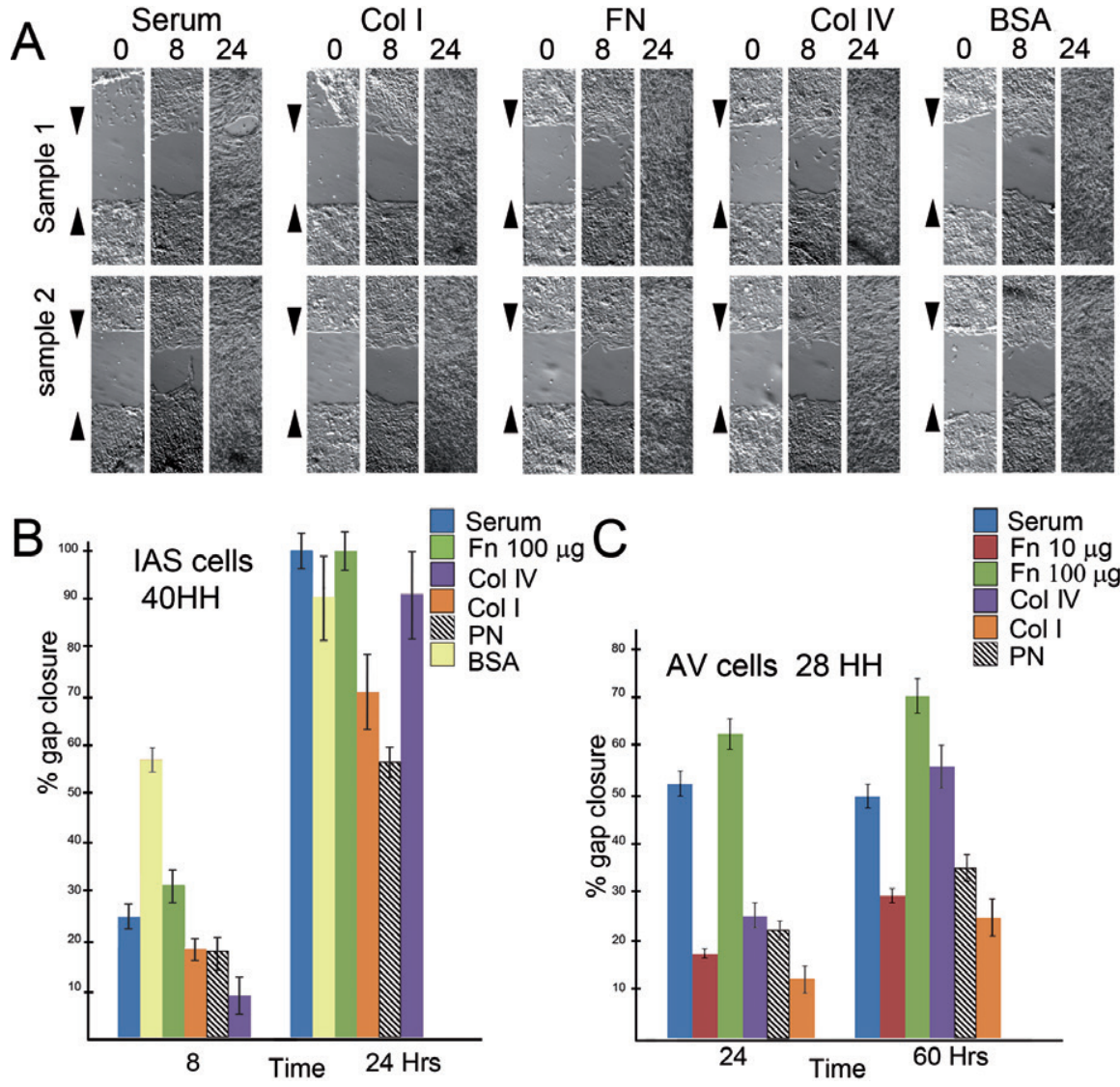

Serum $_{\text {En } 100} \mathrm{C}$

Col IV

Coll

BSA

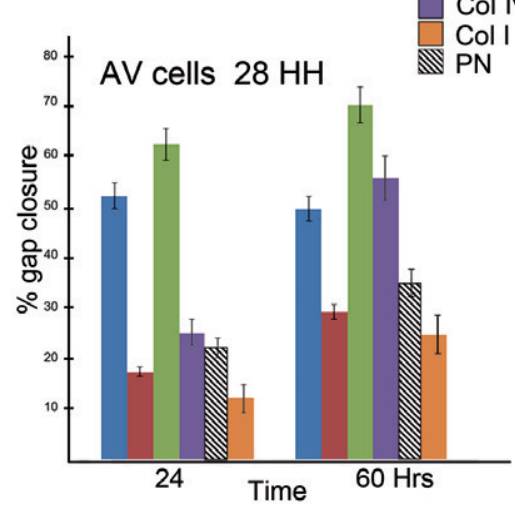

Figure 2. Linear array of multi-substrate cell migration assay-format M (LAMA-M) for comparison of matrix protein-dependent migration between two different embryonic cell populations.

(A) To assess reproducibility of the data, $\mathrm{HH}$ stage 40 chick embryo interatrial septum (IAS) mesenchymal cells were plated $\left(1 \times 10^{4}\right.$ cells in $200 \mu \mathrm{l}$ of medium) in opposing halves of the chamber (Sample 1 vs. Sample 2). After $24 \mathrm{~h}$, the glass partition was removed, and non-adherent cells were washed away with warm media. Images of the gap interface were collected after 0,8 , and $24 \mathrm{~h}$ of incubation. Cell migration was evaluated as the percent closure of the gap (arrowheads). (B) Plot of 3 independent experiments to test inter-chamber variability of $\mathrm{HH}$ stage 40 chick embryo IAS mesenchymal cells after 8 and $24 \mathrm{~h}$ of cell migration on different target matrix proteins. (C) Plot of 3 independent experiments to test inter-chamber variability of $\mathrm{HH}$ stage 28 chick embryo AV mesenchymal cells after 24 and $60 \mathrm{~h}$ of cell migration on different target matrix proteins. Error bars indicate median \pm SE. Test proteins included $5 \% \mathrm{v} / \mathrm{v}$ chicken serum (serum); $10 \mu \mathrm{g} / \mathrm{mL}$ periostin (PN); $10 \mu \mathrm{g} / \mathrm{mL}$ collagen I (Col I); $10 \mu \mathrm{g} / \mathrm{mL}$ (Panel C) or $100 \mu \mathrm{g} / \mathrm{mL}$ (Panels $\mathrm{A}, \mathrm{B}$, and C) fibronectin (FN); $10 \mu \mathrm{g} / \mathrm{mL}$ collagen IV (Col IV); $1 \% \mathrm{v} / \mathrm{v}$ bovine serum albumin (BSA).

The resulting dialysate was diluted with $4 \mathrm{~mL}$ deionized water, then filtered $(0.22$ $\mu \mathrm{m})$ and stored at $-20^{\circ} \mathrm{C}$. The PLL-g-PEG solution was used at a 1:60 dilution in PBS.

Chamber assembly. The LAMA-M module is composed of a glass slide with the attached target proteins (Figure 1A2), the upper $2 \mathrm{C}$-shaped Sylgard 184 molds, and 2 glass coverslips cut to $7 \times 15 \mathrm{~mm}$ and affixed to the lateral side of the upper chamber, resulting in 2 culture compartments. The LAMA-D module is composed of a glass slide with the attached target protein (Figure 1B1) and a square Sylgard 184 mold (Figure 1B2). Following completion of chamber assembly, the paper template for the tunnel mold was removed from the underside of the slide for both modules.

\section{Chick mesenchymal cell isolation}

Chick embryos, Hamburger Hamilton $(\mathrm{HH})$ stages 28 and 40 ( 6 days and 16 days of incubation, respectively), were collected in sterile PBS. Hearts were removed and transferred to fresh, sterile PBS. The left and right atrium and ventricular apex regions were dissected out to expose the whole prospective atrioventricular (AV) apparatus in $\mathrm{HH}$ stage 28 hearts. The right valve was removed from each heart and transferred to fresh PBS. The ventricular apex of $\mathrm{HH}$ stage 40 chick hearts was dissected from the right atrial wall to expose the interatrial septum, which was then removed and transferred to sterile PBS. The $\mathrm{HH}$ stage 28 valve leaflets and the $\mathrm{HH}$ stage 40 interatrial atrial septa were transferred to separate tubes and incubated for $30 \mathrm{~min}$ at room temperature in $2.5 \%$ porcine trypsin (Gibco) with slow agitation, followed by centrifugation at $200 \times g$ for 5 min in an accuSpin 1 microcentrifuge (Fisher Scientific). The supernatant fraction was carefully removed and then resuspended to $10^{5} \mathrm{cell} / \mathrm{s} / \mathrm{mL}$ in M199 medium containing $1 \%$ chicken serum, ITS (5 $\mu \mathrm{g} /$ $\mathrm{mL}$ insulin, $5 \mu \mathrm{g} / \mathrm{mL}$ transferrin, $5 \mathrm{ng} / \mathrm{mL}$ selenium) (Becton Dickinson, San Jose), and penicillin-streptomycin $(100 \mathrm{U} / \mathrm{mL}$ and $100 \mu \mathrm{g} / \mathrm{mL}$, respectively) (Fisher Scientific). Each well of the LAMA-M module received $200 \mu \mathrm{l}$ of this cell suspension. The cultures were incubated at $37^{\circ} \mathrm{C} / 5 \%$ $\mathrm{CO}_{2}$ with humidity at saturation. Culture medium was replaced every other day, as needed.

\section{Cell lines}

PC12 cells were kept in RPMI supplemented with $10 \%$ horse serum, $5 \%$ FBS, and $100 \mathrm{U} / \mathrm{mL}$ and $100 \mu \mathrm{g} / \mathrm{mL}$ penicillinstreptomycin, respectively. Each well received $1 \times 10^{4}$ cells for the LAMA-D model. Medium was changed every 2-3 days. PC12 cells were induced to differentiate by treating with $50 \mathrm{ng} / \mathrm{mL}$ NGF and replenishing with medium containing NGF every other day. The degree of differentiation was scored after 5-7 days.

Mouse embryonic stem cells (mESCs) expressing green fluorescent protein (GFP) regulated by the $\alpha$ myosin heavy chain promoter were used to assess their differentiation into myocardial cells. The mESCs were plated $\left(1 \times 10^{4}\right.$ cells per well) and treated with a cocktail of growth/differentiation factors to induce a myocardial phenotype. Medium was replaced every other day. The degree of differentiation was assessed on day 7. Both cell types (PC12 and $\mathrm{mESC}$ ) were cultured at $37^{\circ} \mathrm{C}$ in a $5 \% \mathrm{CO}_{2} / 95 \%$ air atmosphere with humidity at saturation.

\section{Results and discussion}

We sought to circumvent the limitations of current adhesion/migration/differentiation model systems, which only allow for testing one substrate condition at a time. Our study describes two new culture models, one for assessing the relative 
effects of different matrix molecules on cell migration in parallel (LAMA-M) and another to similarly test the effects of multiple matrix molecules in parallel on cell adhesion/differentiation (LAMA-D). These models can compare up to 20 substrates in the same chamber under the same culture conditions (Figure 1). Both models utilize a tunnel reaction chamber, with each tunnel being used to covalently attach an array of matrix constituents to microchannels on a glass slide. The protein arrays were created in three steps: (i) derivatizing the glass surface with free $\mathrm{NH}_{2}$ groups in order to (ii) attach a bifunctional cross-linking reagent that was used to (iii) covalently attach proteins of interest in each reaction tunnel. Proteins that do not have available sulfhydryl groups can be attached using other functional side groups. Diagrams of the completed LAMA-M and LAMA-D culture chambers are presented in Figure 1, A2 and B2, showing hypothetical experimental results for both models in Figure 1, A3, A4, B3, and B4.

Several different approaches were tried to create the reaction tunnels before we discovered that the internal ridges of a Costar syringe filter (see above) offered a convenient, inexpensive, and reliable template for casting a mold with the desired channel dimensions. The polyvinyl chloride (PVC) housing is compatible with the Sylgard matrix, resulting in uniform spreading and no bubbles. Another initial challenge was aligning the LAMA-M and LAMA-D culture chambers to the test protein lanes. We found that adhering a temporary paper template on the bottom of the glass slide was an easy way to guide the proper attachment of the culture chamber molds.

The literature shows that there are differences in cell behavior on fibronectin coated passively onto plastic dishes, presumably due to protein denaturation or variable availability of functional motifs. Studies such as those by Garcia et al. (38) have used differential accessibility of monoclonal antibodies to assess the molecular structure of fibronectin attached to substrates. While, in theory, one might expect such an ELISA method to work for assessing the LAMA molds, the surface area of a well in a 96-well plate is $160 \times$ greater than for that created by a LAMA tunnel, which would
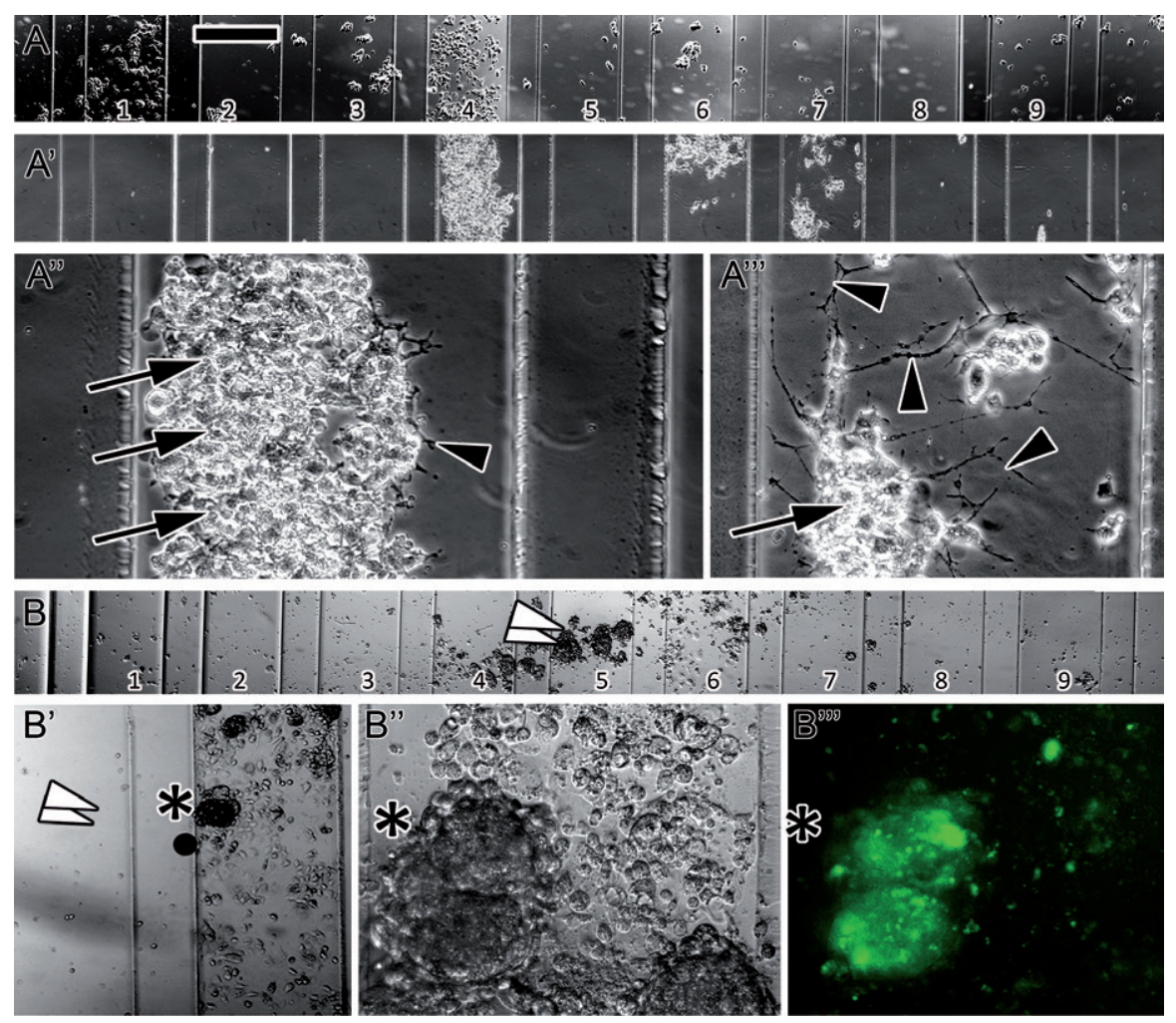

Figure 3. Linear array of multi-substrate cell migration assay (LAMA) format comparing adhesion/differentiation (LAMA-D) of two different cell lines. PC12 cells $\left(1 \times 10^{4}\right.$ in $\left.500 \mu \mathrm{l}\right)$ were plated on the chamber shown in Figure 1B3. The enclosure was removed after $24 \mathrm{~h}$, and the free (non-attached) cells were washed with warm media. (A, $A^{\prime}$ ) After 3 days of culture, most of the cells were not attached to the surface and were removed when the medium was exchanged with fresh warm medium; compare with A'. Note that only cells on collagen IV (Lane 4 in A') and collagen I (Lanes 6 and 7 in A') remained attached (homogeneous attachment on the collage IV lane, but not on the collagen I lanes). PC12 cells that were induced to differentiate by treatment with $50 \mathrm{ng} / \mathrm{mL}$ nerve growth factory (NGF) for 5 days express the chromaffin (arrows) and dendritic phenotypes (arrow heads). Note that more chromaffin cells than dendritic cells grew on collagen IV (A"), while the opposite occurred on collage I (A"'). The protein concentrations used per lane were: fibronectin, $100 \mu \mathrm{g} / \mathrm{mL}$ (Lane 1), $50 \mu \mathrm{g} / \mathrm{mL}$ (Lane 2), $10 \mu \mathrm{g} / \mathrm{mL}$ (Lane 3); collagen IV, $10 \mu \mathrm{g} / \mathrm{mL}$ (Lane 4); periostin, $100 \mu \mathrm{g} / \mathrm{mL}$ (Lane 5); collagen I, $100 \mu \mathrm{g} / \mathrm{mL}$ (Lanes 6 and 7); serum, $5 \%$ (Lane 8); and hyaluronic acid, $100 \mu \mathrm{g} / \mathrm{mL}$ (Lane 9). The scale bar represents $0.5 \mathrm{~mm}$. (B) Mouse embryonic stem cells (mESCs) were plated on a chamber as shown in Figure 2B. The enclosure was removed after $24 \mathrm{~h}$, and the non-adherent cells (double white arrowhead) were washed away with warm medium (see double white arrowhead in Panel B'). Note that only mESCs remain attached homogeneously only on collagen I (Lane 6). By day 7, some cells acquired a fibroblastic phenotype ( ${ }^{*}$ in Panel B'), while others acquired a myocardial phenotype where they expressed GFP under the regulation of the $\alpha$ myosin heavy chain promoter (Panels B" and B"') and were beating (not shown). The protein concentrations used ( $\mu \mathrm{g} / \mathrm{mL})$ were: fibronectin, $100 \mu \mathrm{g} / \mathrm{mL}$ (Lane 1), $50 \mu \mathrm{g} / \mathrm{mL}$ (Lane 2), $10 \mu \mathrm{g} / \mathrm{mL}$ (Lane 3); collagen IV, $10 \mu \mathrm{g} / \mathrm{mL}$ (Lane 4); periostin, $100 \mu \mathrm{g} / \mathrm{mL}$ (Lane 5); collagen I, $100 \mu \mathrm{g} / \mathrm{mL}$ (Lane 6); serum, 5\% (Lane 7); hyaluronic acid, $100 \mu \mathrm{g} / \mathrm{mL}$ (Lane 8); fibronectin, $100 \mu \mathrm{g} / \mathrm{mL}$ (Lane 9). The asterisks denote the same area in Panels B', B" and B'".

\section{LOSE THE WOBBLE! LOSE THE DRIP!}

Unique, innovative, patented 2-tier step design:

- Less Force needed to insert

- 2X contact in your controller's nozzle

- Less Jamming AND Less Wobble!

- Less Wobble means Less Dripping!

-Works with ANY pipet controller

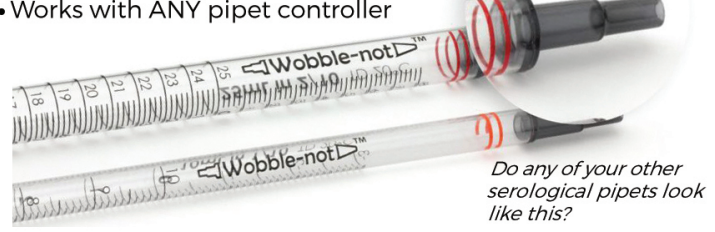

ETWoble-notD

The first-ever ergonomic Serological Pipet 
account for our inability to demonstrate the distribution of matrix proteins in our model system. Others have explored the molecular conformations of fibronectin on different surfaces using atomic force microscopy (39), but that is beyond the scope of the present study.

The LAMA-M model was used to compare the migration characteristics of different sources of mesenchymal cells from embryonic chick hearts (Figure 2). First, we assessed reproducibility by culturing 2 independent isolates of only interatrial septum mesenchymal cells in duplicate (Samples 1 and 2), which gave similar results for gap closure from 8 to 24 h (Figure 2A). Next, we compared two different sources of embryonic chick heart mesenchymal cells (interatrial septum mesenchymal cells and AV cushion cells) on an array of different matrix substrates. As shown in Figure 2, $B$ and $C$, the interatrial septum mesenchymal cells migrated faster than the atrioventricular cells, depending on the target substrate. Importantly, the extent of migration was dependent on fibronectin concentration $(10 \mu \mathrm{g} / \mathrm{mL}$ versus $100 \mu \mathrm{g} / \mathrm{mL}$ ) (Figure 2). The enhanced migration of embryonic mesenchymal cells is similar to what has previously been reported for fibroblasts (40-42).

To test the utility of the LAMA-D model, we compared two cell lines, one for neuronal differentiation (PC12) $(43,44)$ and the other for myocardial differentiation (mESC) (45). PC12 cells were chosen because they recapitulate several characteristics of neuronal differentiation when stimulated with NGF $(43,44) . P C 12$ is a cell line derived from a neuroendocrine tumor of the rat adrenal medulla. When treated with NGF, PC12 cells stop dividing and terminally differentiate. PC12 cells cultured in the LAMA-D model attached preferentially to both type I and IV collagen-coated surfaces (Figure 3A-A') and exhibited a neuronal phenotype as characterized by the expression of neural chromaffin (Figure 3A", arrows) and dendritic morphologies (Figure 3A", arrowheads) when treated with NGF. After 3 days in culture, most of the PC12 cells were loosely attached to fibronectin or periostin, resulting in the cells being washed away when the culture medium was changed (compare Figure 3A versus $\left.3 A^{\prime}\right)$. Note that PC12 cells only remained attached to collagen
IV (Lane 4 in Figure 3A') and collagen I (Figure 3A', Lanes 6 and 7) after the medium was changed; however, there appeared to be a preference for cell retention on collagen IV over collagen I. It should also be noted that NGF-treated PC12 cultures appeared to contain more chromaffin cells than dendritic cells on collagen IV, while the converse occurred on collagen I (compare Figure 3A" versus 3A'"'). The LAMA-D model was also used to test the capacity of mESCs to express characteristics of a myocardial phenotype when grown on different ECM constituents (Figure 3B). mESCs were cultured in a LAMA-D chamber for $24 \mathrm{~h}$ prior to removal of the glass partition to allow cells to attach and migrate on the varied ECM substrates. Note that mESCs remained attached in a continuous sheet only on collagen I (Figure 3B, Lane 6), while mESCs did not attach to other test substrates and were washed away when processing the sample for analysis (see double white arrowhead in B'). By day 7, some mESCs acquired fibroblastic characteristics and others a myocardial phenotype, as evidenced by the expression of GFP under the regulation of the $\alpha$ myosin heavy chain promoter (* in Figure 3B', 3B"' and 3B'"').

Here, we developed a culture system for directly comparing how cells respond to a linear array of different proteins or possible candidates, to study in parallel, cell migration, adhesion, and differentiation, using minute amounts of test proteins and cells. Our LAMA-M and LAMA-D culture models minimize reagent costs by reducing the amounts of test compounds and reagents. A modification of the model allows for a direct comparison of behavior between two cell types in a single system. It is possible that, with minor modifications, one could similarly study galvanotaxis on different substrates. In addition, by using robotic processing to make the mold, it would be possible to increase the number of channels to 50 per $10 \mathrm{~mm}$

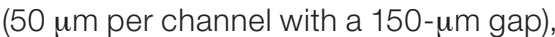
allowing the study of up to 100 different substrates. Since it is possible to use different concentrations or replicates of the same substrate at the same time, this new design will also allow study of possible interactions or crosstalk between cells and substrates affecting cell migration on the neighboring tract.
This new design provides enormous flexibility in controlling the critical biochemical and biomechanical factors influencing cell behavior, is compatible with varied microscopic methods of analysis, and uses only limited numbers of cells and minimal amounts of expensive test reagents.

\section{Author contributions}

R.A.M.-R. conceived and designed the method, performed analysis on all samples, interpreted data, wrote manuscript and acted as corresponding author. E.L.K. discussed the experimental results and edited the manuscript. L.R. performed and discussed the PC12 experiments as well as the cushion cell isolation from chick embryos. R.R.M. contributed to development of the work and assisted with data interpretation, manuscript evaluation, and editing.

\section{Acknowledgments}

Mouse embryonic stem cells were kindly provided by Ann C. Foley (Clemson University). The PC12 cells were kindly provided by Kenneth D. Tew (MUSC). We thank Aldo Moreno-Reyes for the sketch in Autodesk shown in Fig 1A. We thank William Lafayette Mondy for helpful comments/critiques on an earlier version of this article. This work was sponsored in part by the National Institutes of Health (NIH): HL33756 and NIGMSCOBRE P2ORR 016434. This paper is subject to the NIH Public Access Policy.

\section{Competing interests}

The authors declare no competing interests.

\section{References}

1. Hulkower, K.I. and R.L. Herber. 2011. Cell migration and invasion assays as tools for drug discovery. Pharmaceutics 3:107-124.

2. Vedula, S.R., A. Ravasio, C.T. Lim, and B. Ladoux. 2013. Collective cell migration: a mechanistic perspective. Physiology (Bethesda) 28:370-379.

3. Fujimoto, T., A. Ukeshima, and R. Kiyofuji. 1976. The origin, migration and morphology of the primordial germ cells in the chick embryo. Anat. Rec. 185:139-145.

4. Moreno-Rodriguez, R.A., E.L. Krug, L. Reyes, G. Villavicencio, C.H. Mjaatvedt, and R.R. Markwald. 2006. Bi-directional fusion of the heart forming fields in chick. Dev. Dyn. 235:191-202

5. Richardson, B.E. and R. Lehmann. 2010. Mechanisms guiding primordial germ 
cell migration: strategies from different organisms. Nat. Rev. Mol. Cell Biol. 11:37-49.

6. Wolf, K., I. Mazo, H. Leung, K. Engelke, U.H. von Andrian, E.I. Deryugina, A.Y. Strongin, E.B. Bröcker, and P. Friedl. 2003. Compensation mechanism in tumor cell migration: mesenchymal-amoeboid transition after blocking of pericellular proteolysis. J. Cell Biol. 160:267-277

7. Akhmanova, M., E. Osidak, S. Domogatsky, S. Rodin, and A. Domogatskaya. 2015. Physical, spatial, and molecular aspects of extracellular matrix of in vivo niches and artificial scaffolds relevant to stem cells research. Stem Cells Int. 2015:167025.

8. Bissell, M.J., H.G. Hall, and G. Parry. 1982. How does the extracellular matrix direct gene expression? J. Theor. Biol. 99:31-68

9. McCarthy, J.B., S.L. Palm, and L.T. Furcht. 1983. Migration by haptotaxis of a Schwann cell tumor line to the basement membrane glycoprotein laminin. J. Cell Biol. 97:772-777.

10. Woo, C.H., H.J. You, S.H. Cho, Y.W. Eom, J.S. Chun, Y.J. Yoo, and J.H. Kim. 2002. Leukotriene B(4) stimulates Rac-ERK cascade to generate reactive oxygen species that mediates chemotaxis. J. Biol. Chem. 277:8572-8578.

11. Liu, Z. and J. Klominek. 2004. Chemotaxis and chemokinesis of malignant mesothelioma cells to multiple growth factors. Anticancer Res. 24:1625-1630.

12. Wong, C.H.Y., B. Heit, and P. Kubes. 2010. Molecular regulators of leucocyte chemotaxis during inflammation. Cardiovasc. Res. 86:183-191.

13. Sackmann, E.K., E. Berthier, E.W. Young, M.A. Shelef, S.A. Wernimont, A. Huttenlocher, and D.J. Beebe. 2012. Microfluidic kit-on-a-lid: a versatile platform for neutrophil chemotaxis assays. Blood 120:e45-e53.

14. Nie, F.Q., M. Yamada, J. Kobayashi, M. Yamato, A. Kikuchi, and T. Okano. 2007. On-chip cell migration assay using microfluidic channels. Biomaterials 28:4017-4022.

15. van der Meer, A.D., K. Vermeul, A.A. Poot, J. Feijen, and I. Vermes. 2010. A microfluidic wound-healing assay for quantifying endothelial cell migration. Am. J. Physiol. Heart Circ. Physiol. 298:H719-H725.

16. Saadi, W., S.W. Rhee, F. Lin, B. Vahidi, B.G. Chung, and N.L. Jeon. 2007. Generation of stable concentration gradients in $2 D$ and $3 D$ environments using a microfluidic ladder chamber. Biomed. Microdevices 9:627-635

17. Ashby, W.J. and A. Zijlstra. 2012. Established and novel methods of interrogating two-dimensional cell migration. Integr Biol (Camb). 4:1338-1350.

18. Chen, Y.C., S.G. Allen, P.N. Ingram, R. Buckanovich, S.D. Merajver, and E. Yoon. 2015. Single-cell Migration Chip for Chemotaxis-based Microfluidic Selection of Heterogeneous Cell Populations. Sci. Rep. 5:9980.

19. Sackmann, E.K., A.L. Fulton, and D.J. Beebe. 2014. The present and future role of microfluidics in biomedical research. Nature 507:181-189.

20. Kramer, N., A. Walzl, C. Unger, M. Rosner, G. Krupitza, M. Hengstschläger, and $\mathrm{H}$. Dolznig. 2013. In vitro cell migration and invasion assays. Mutat. Res. 752:10-24.
21. Mycielska, M.E. and M.B. Djamgoz. 2004 Cellular mechanisms of direct-current electric field effects: galvanotaxis and metastatic disease. J. Cell Sci. 117:1631-1639.

22. Cohen, D.J., W.J. Nelson, and M.M. Maharbiz. 2014. Galvanotactic control of collective cell migration in epithelial monolayers. Nat. Mater. 13:409-417.

23. Babona-Pilipos, R., M.R. Popovic, and C.M. Morshead. 2012. A galvanotaxis assay for analysis of neural precursor cell migration kinetics in an externally applied direct current electric field. J. Vis. Exp. 13:pii 4193.

24. Al Tanoury, Z., A. Piskunov, D. Andriamoratsiresy, S. Gaouar, R. Lutzing, T. Ye, B. Jost, C. Keime, and C. Rochette-Egly. 2014. Genes involved in cell adhesion and signaling: a new repertoire of retinoic acid receptor target genes in mouse embryonic fibroblasts. J. Cell Sci. 127:521-533.

25. Schiller, K.R., P.J. Maniak, and S.M. O'Grady. 2010. Cystic fibrosis transmembrane conductance regulator is involved in airway epithelial wound repair. Am. J. Physiol. Cell Physiol. 299:C912-C921.

26. Liang, C.C., A.Y. Park, and J.L. Guan. 2007. In vitro scratch assay: a convenient and inexpensive method for analysis of cell migration in vitro. Nat. Protoc. 2:329-333.

27. Behrens, J., P. Kameritsch, S. Wallner, U. Pohl, and K. Pogoda. 2010. The carboxyl tail of Cx43 augments p38 mediated cell migration in a gap junction-independent manner. Eur. J. Cell Biol. 89:828-838.

28. Markwald, R.R., D.L. Bolender, E.L. Krug, and R. Lepera. 1990. Morphogenesis of precursor subpopulations of chicken limb mesenchyme in three dimensional collagen gel culture. Anat. Rec. 226:91-107.

29. Hakkinen, K.M., J.S. Harunaga, A.D. Doyle, and K.M. Yamada. 2011. Direct Comparisons of the Morphology, Migration, Cell Adhesions, and Actin Cytoskeleton of Fibroblasts in Four Different Three-Dimensional Extracellular Matrices. Tissue Eng. Part A 17:713-724.

30. Piner R.D., J. Zhu, F. Xu, S. Hong, and C.A. Mirkin. 1999. “Dip-pen” nanolithography. Science 283:661-663

31. Théry, M. 2010. Micropatterning as a tool to decipher cell morphogenesis and functions. J. Cell Sci. 123:4201-4213.

32. Kim, J., J. Cho, P.M. Seidler, N.E. Kurland, and V.K. Yadavalli. 2010. Investigations of chemical modifications of amino-terminated organic films on silicon substrates and controlled protein immobilization. Langmuir 26:2599-2608

33. Nakanishi, K., T. Sakiyama, and K. Imamura. 2001. On the adsorption of proteins on solid surfaces, a common but very complicated phenomenon. J. Biosci. Bioeng. 91:233-244

34. Lu, J., K. Kaestle, J. Huang, Q. Liu, P. Zhang, L. Gao, J. Gardiner, H. Thissen, and H.-T. Yang. 2017. Interactions of human embryonic stem cell-derived cardiovascular progenitor cells with immobilized extracellular matrix proteins. J Biomed Mater Res A. 105:1094-1104.

35. Ballet, T., L. Boulange, Y. Brechet, F. Bruckert, and M. Weidenhaupt. 2010. Protein conformational changes induced by adsorption onto material surfaces: an important issue for biomedical applications of material science. Bull Polish Academy Sciences 58:303-315.

36. Chan, L., H.F. Cross, J.K. She, G. Cavalli, H.F.P. Martins, and N. Cameron. 2007. Covalent Attachment of Proteins to Solid Supports and Surfaces via Sortase-Mediated Ligation. PLoS One 2:e1164.

37. Huang, N.P., R. Michel, J. Voros, M. Textor, R. Hofer, A. Rossi, D.L. Elbert, J.A. Hubbell, and N.D. Spencer. 2001. Poly(L-lysine)-g-poly(ethylene glycol) layers on metal oxide surfaces: Surface-analytical characterization and resistance to serum and fibrinogen adsorption. Langmuir 17:489-498.

38. García, A.J., M.D. Vega, and D. Boettiger. 1999. Modulation of cell proliferation and differentiation through substrate-dependent changes in fibronectin conformation. Mol. Biol. Cell 10:785-798.

39. Bergkvist, M., J. Carlsson, and S. Oscarsson. 2003. Surface-dependent conformations of human plasma fibronectin adsorbed to silica, mica, and hydrophobic surfaces, studied with use of Atomic Force Microscopy. J Biomed Mater Res A. 64:349356.

40. Postlethwaite, A.E., J. Keski-Oja, G. Balian, and A.H. Kang. 1981. Induction of fibroblast chemotaxis by fibronectin. Localization of the chemotactic region to a 140,000-molecular weight non-gelatinbinding fragment. J. Exp. Med. 153:494-499.

41. Palecek, S.P., J.C. Loftus, M.H. Ginsberg, D.A. Lauffenburger, and A.F. Horwitz. 1997. Integrinligand binding properties govern cell migration speed through cellsubstratum adhesiveness. Nature 385:537540.

42. Rajagopalan, P., W.A. Marganski, X.Q. Brown, and J.Y. Wong. 2004. Direct comparison of the spread area, contractility, and migration of balb/c 3T3 fibroblasts adhered to fibronectin- and RGD-modified substrata. Biophys. J. 87:2818-2827.

43. Tomaselli, K.J., C.H. Damsky, and L.F. Reichardt. 1987. Interactions of a neuronal cell line (PC12) with laminin, collagen IV, and fibronectin: identification of integrin-related glycoproteins involved in attachment and process outgrowth. J. Cell Biol. 105:23472358.

44. Paralkar, V.M., B.S. Weeks, Y.M. Yu, H.K. Kleinman, and A.H. Reddi. 1992. Recombinant human bone morphogenetic protein 28 stimulates PC12 cell differentiation: potentiation and binding to type IV collagen. J. Cell Biol. 119:1721-1728.

45. Foley, A. and M. Mercola. 2004. Heart Induction: Embryology to Cardiomyocyte Regeneration. Trends Cardiovasc. Med. 14:121-125.

Received 27 December 2016; accepted 26 October 2017.

Address correspondence to Ricardo A. MorenoRodriguez, Department of Regenerative Medicine and Cell Biology, Medical University of South Carolina, Charleston, SC. E-mail: morenor@musc.edu

To purchase reprints of this article, contact: biotechniques@fosterprinting.com 